
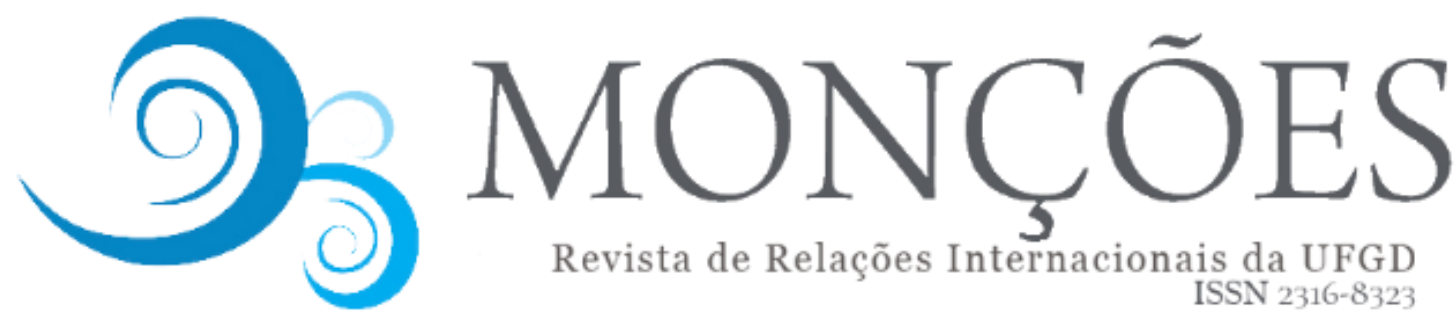

Revista de Relações Internacionais da UFGD

ISSN 2316-8323

\title{
ENTREVISTA CON MARIA ELENA ATTARD BELLIDO
}

\section{Entrevistadores}

JOÃO NACKLE URT

Professor da Faculdade de Direito e Relações Internacionais da Universidade Federal da Grande Dourados (UFGD), Dourados (MS), Brasil. ORCID: https://orcid.org/0000-0002-7785-2450

joaourt@ufgd.edu.br

MÁRCIO SECCO

Professor do Departamento de Filosofia da Universidade Federal de Rondônia,

Porto Velho, Brasil.

ORCID: https://orcid.org/0000-0001-7648-8522

msecco@unir.br

PATRÍCIA MARA CABRAL DE VASCONCELLOS

Professora do Departamento de Ciências Sociais (DACS) da Universidade

Federal de Rondônia (Unir), Porto Velho (RO), Brasil.

ORCID: https://orcid.org/0000-0002-9077-8734

pvasconcellos@unir.br

María Elena Attard Bellido es una abogada boliviana, con estudios de postgrado y especialización en derecho constitucional, procesal constitucional, derechos humanos, género, pluralismo jurídico y derechos de los pueblos indígenas. Letrada del Tribunal Constitucional Plurinacional, realizó la sistematización de toda la jurisprudencia constitucional en el Estado Plurinacional de Bolivia. Es docente en postgrado de varias universidades de Bolivia, entre ellas Universidad Andina Simón Bolivia, Universidad Mayor de San Andrés UMSA, Universidad Mayor de San Simón UMSS, Universidad Gabriel René Moreno, Universidad San Francisco Xavier de Chuquisaca USXCH, Universidad Amazónica de Pando, Universidad Juan Misael Saracho, Universidad Tomás Frías, Universidad Siglo XX, Universidad del Valle, Escuela de Jueces del Estado, Escuela de Fiscales del Estado, Escuela de Gestión Pública. Actualmente hace la coordinación académica de la Maestría en Administración de Justicia con enfoque en 
derechos humanos de la Universidad Chiquitana, dirigida a autoridades judiciales y fiscales en la Amazonía boliviana. También forma parte de la Clínica Jurídica para el litigio estratégico de derechos de la Fundación Construir y está vinculada a la red de mujeres constitucionalistas latinoamericanas.

Pregunta: Basado en premisas teóricas, ¿cómo evalúa la importancia del giro decolonial para una nueva visión de la historia de los países amazónicos? ¿Cuáles serían las implicaciones de un giro decolonial para los derechos de la población tradicional amazónica?

Respuesta: La corriente del giro decolonial sustentada por diversas voces de teorías críticas, identifica a la colonización como la causa directa de la construcción de históricas relaciones de jerarquización, discriminación, injusticias y opresión, especialmente en relación a los pueblos indígenas, las cuales han perdurado en el tiempo a través de un histórico silenciamiento a las voces de los históricamente oprimidos, generando de esta manera sociedades con profundas brechas de desigualdad, desequilibrios y exclusión.

En el contexto latinoamericano, el giro decolonial cuestiona la dominante epistemología euro-céntrica y monocultural, para una desjerarquización de las sociedades, para que así, en el marco de los diversos saberes, culturas, cosmovisiones y espiritualidades, mediante procesos de traducción y entendimiento, se construyan y generen epistemologías de fuentes plurales e interdialógicas a partir de la voz directa de los históricamente oprimidos.

Entonces, de acuerdo al giro decolonial, no existe cultura superior a otra, sino más bien todas se complementan a través de los diálogos polifónicos, horizontales y desjerarquizados, generando de esta forma escenarios propicios para la coexistencia en armonía, reciprocidad y complementariedad de plurales sistemas políticos, económicos o jurídicos.

Como puede advertirse, el giro decolonial cuestiona las históricas relaciones de jerarquización, exclusión, discriminación e invisibilización a los pueblos indígenas en Latinoamérica; planteando un horizonte emancipatorio destinado a reivindicar sus derechos en plena armonía con sus cosmovisiones, sus saberes 
ancestrales, sus espiritualidades, sus normas, sus sistemas jurídicos, políticos y económicos.

Este horizonte emancipatorio, tan necesario para los pueblos amazónicos, sin duda, plantea un desmontaje a los históricos modelos de Estado monocultural, que a través de sus leyes y estructura orgánica, promovieron y sustentaron la discriminación, el racismo, la exclusión e invisibilización de los históricamente oprimidos; entonces, el giro decolonial invita a los pueblos amazónicos a la reivindicación de un Estado plurinacional, en el cual, la construcción plural de derechos y su plena participación en las estructuras estatales no sea una quimera, sino una realidad.

Pregunta: ¿Sería posible afirmar que el pluralismo jurídico es una forma de lucha contrahegemónica para desafiar los proyectos de modernización y la deslegitimación de las poblaciones tradicionales, basadas en una visión del colonialismo contemporáneo? ¿Qué sería superar la "lógica de la colonialidad de las sentencias"?

Respuesta: Como ya se señaló, el giro decolonial plantea un desmontaje del Estado monocultural, en el cual, prevalece la ley como única fuente de derecho, el sufragio universal como la mejor alternativa democrática y la justicia ordinaria como la única forma oficial de resolución de conflictos para asegurar la paz social; en este escenario, las reflexiones sobre otras formas de construcción plurinacional de las estructuras estatales vienen de las voces críticas y las teorías decoloniales, que impulsan el fortalecimiento y vigencia plena de los sistemas jurídicos de los pueblos indígenas en igualdad jerárquica con la jurisdicción ordinaria y en un contexto de pluralismo de fuentes jurídicas.

En efecto, el pluralismo jurídico igualitario, es consustancial al Estado plurinacional, el cual, en un marco de complementariedad, puede ser consagrado en estructuras unitarias, en modelos autonómicos o federales de Estado. En esta perspectiva, un Estado plurinacional, en coherencia con la cláusula de libre determinación de los pueblos indígenas, de acuerdo a una pluralidad epistémica, asegurará el respeto de los variados sistemas jurídicos, en igualdad jerárquica con la jurisdicción ordinaria. 
Asimismo, un modelo de Estado plurinacional, desde los pilares del giro decolonial, asegura el reconocimiento como fuente directa derecho a las diversas normas y procedimientos de los pueblos indígenas que puedan emanar de sus formas de democracia comunitaria y sus sistemas políticos.

Si la ley del hombre blanco, letrado y católico fue una histórica herramienta de opresión para los pueblos indígenas, sin duda, el pluralismo jurídico de tipo igualitario y el reconocimiento de otras formas de democracia como la comunitaria, están destinadas a desmontar estructuras jerarquizadas y excluyentes, por lo que sin duda, el pluralismo jurídico igualitario cumple una función de lucha contrahegemónica para desafiar los proyectos de modernización y de deslegitimación de los pueblos indígenas.

Además, es importante señalar que el monopolio de la justicia ordinaria subordinada a la ley, la cual debe ser aplicada por las autoridades judiciales a través de la sentencia, fue también un mecanismo opresor para los pueblos indígenas, por tanto, el pluralismo jurídico igualitario, está destinado a superar la colonialidad de las sentencias y a generar, desde las diversas cosmovisiones, procesos distintos de traducción y entendimiento para vivir bien y en armonía.

Pregunta: ¿Puede pensar en ejemplos de conflictos en la Amazonía que podrían abordarse o resolverse siguiendo las premisas del pluralismo jurídico? Nos gustaría escuchar sobre experiencias exitosas basadas en la constitución boliviana.

Respuesta: La Constitución boliviana, a la luz de los principios constitucionales de la plurinacionalidad, el pluralismo y la interculturalidad, ha desarrollado un sistema plural de control de constitucionalidad a través de procedimientos constitucionales enmarcados a procesos de diálogo interjurisdiccional e intercultural entre los pueblos indígenas y el Tribunal Constitucional Plurinacional, en ese marco, uno de estos procedimientos es el de consulta de autoridades de naciones y pueblos indígenas en relación a la aplicación de sus normas (Artículo 202.8 de la Constitución).

A partir de este procedimiento constitucional intercultural, podemos identificar casos emblemáticos, entre ellos el de la comunidad de Zongo, un 
pueblo indígena ubicado en el Departamento de La Paz, el cual, de acuerdo al derecho a la libre determinación consagrado por el artículo 2 de la Constitución, a través de sus sistemas políticos y en ejercicio de sus normas, procedimientos, cosmovisiones, decidió expulsar a un empresario minero de la comunidad.

Esta decisión fue sometida a control de constitucionalidad a través del referido proceso de consulta de autoridades de naciones y pueblos indígenas en relación a la aplicación de sus normas. En este proceso constitucional, la comunidad alegó que la decisión comunitaria de expulsión fue asumida porque los beneficios de la explotación de sus recursos no eran distribuidos en la comunidad y porque dicho empresario se negaba a cumplir con las obligaciones comunitarias establecidas para cualquier tipo de explotación minera en el territorio ancestral de la comunidad.

El Tribunal Constitucional Plurinacional, luego de establecer estándares jurisprudenciales más altos en cuanto al pluralismo jurídico igualitario y la cláusula de libre determinación, a partir de una interpretación de derechos con enfoque intercultural, en la Declaración Constitucional Plurinacional DCP 0006/2013 de 5 de junio de 2013 ${ }^{1}$, determinó la compatibilidad de la decisión con la Constitución boliviana.

En este mismo procedimiento constitucional, el Tribunal Constitucional Plurinacional, en otro caso emblemático referente a la ancestral Nación Uru Chipaya, ubicada en el Departamento de Oruro, en el marco del pluralismo de fuentes jurídicas, consagró el ejercicio de la democracia comunitaria reconocida en el art. 11.3 de la Constitución.

En este caso, el pueblo indígena a través de sus instancias representativas y de acuerdo a la democracia comunitaria, eligió a Elías Felipe Villca como Alcalde de Chipaya, el cual fue luego sometido a sufragio universal, porque todavía el órgano electoral no consagra el acceso directo a estas instancias de los pueblos indígenas a través de la democracia comunitaria.

Posteriormente, el pueblo indígena, en Asamblea General, a través de sus normas y procedimientos decidió cesar del cargo a este alcalde y eligió a otro

\footnotetext{
${ }^{1}$ Sentencia disponible en:

https://buscador.tcpbolivia.bo/_buscador/(S(lii4yxee3ai0bzvka4v3qht4))/WfrResoluciones1.aspx
} 
miembro de la comunidad, decisión que fue incumplida por Elías Felipe Villca, por lo que las autoridades de esta nación, consultaron al Tribunal Constitucional Plurinacional la compatibilidad de su decisión de cese de funciones con la Constitución.

El Tribunal Constitucional Plurinacional, desde un enfoque intercultural de derechos, realizó una ponderación intercultural que contempló el mandato constitucional que consagra la democracia constitucional y la protección a candidatos electos para evitar renuncias forzadas establecidas en la ley electoral.

El máximo contralor de constitucionalidad, en el marco de la vigencia plena de un pluralismo jurídico de tipo igualitario que consagra a las normas y procedimientos de los pueblos indígenas como fuente directa de derecho y a la luz de la democracia comunitaria, estableció en el caso concreto la prevalencia de la decisión comunitaria en relación a la ley y por lo tanto mediante DCP 0030/2014 de 26 de mayo de 2014², declaró la compatibilidad de su decisión con la Constitución.

También podemos identificar otro caso emblemático en relación a un pueblo indígena de la Amazonía, el pueblo Takana El Turi Manupare II, el cual, denunció a través de una acción popular -que es un mecanismo tutelar para la protección de derechos colectivos de pueblos indígenas-, la vulneración a su derecho a la territorialidad y a la consulta previa entre otros, ya que el Estado, otorgó una concesión forestal a un particular en tierras ancestrales de este pueblo indígena amazónico.

En este caso, los miembros de este pueblo ingresaron a esta zona en concesión forestal a recolectar la castaña, como lo hacían ancestralmente; sin embargo, con violencia, fueron expulsados de su territorio por el concesionario, que además se amparó en una decisión del juez agroambiental de la zona, la cual desconoció todos los derechos a la territorialidad de este pueblo indígena.

El Tribunal Constitucional Plurinacional, en la Sentencia Constitucional Plurinacional 0572/2014 de 10 de marzo de 2014³, concedió la acción popular,

\footnotetext{
${ }^{2}$ Sentencia disponible en:

https://buscador.tcpbolivia.bo/_buscador/(S(lii4yxee3aiObzvka4v3qht4))/WfrResoluciones1.aspx ${ }^{3}$ Ibid.
} 
desarrolló el derecho al hábitat desde la cosmovisión indígena y determinó la vulneración de los derechos a la territorialidad y la consulta previa.

Además, en la referida sentencia constitucional plurinacional, desde un enfoque de interculturalidad, consagró el principio de presunción de ancestralidad, a partir del cual, en un Estado plurinacional, caracterizado por la existencia precolonial de diversos pueblos indígenas, antes de otorgar una concesión o una dotación territorial a favor de particulares, se debe aplicar el referido principio, para priorizar así la dotación de tierras comunitarias a pueblos indígenas en el marco de su derecho a la territorialidad.

Además, esta sentencia estableció el deber del Estado Plurinacional de Bolivia, de cumplir con la consulta previa antes de establecer concesiones forestales, deber que, debe sujetarse al principio de presunción de ancestralidad antes referido.

Estos casos emblemáticos, significaron un avance importante en la jurisprudencia del Tribunal Constitucional Plurinacional y de acuerdo al principio de progresividad, podrían ser considerados por otras cortes de la Región en resguardo de derechos de los pueblos indígenas y especialmente de los pueblos amazónicos.

Pregunta: ¿Cuáles son los retos para que los derechos indígenas sean respetados de acuerdo con la Convención n. 169 de la OIT, cuyo artículo 8.1 establece la obligación internacional de considerar las costumbres y el derecho consuetudinario de los pueblos indígenas?

Respuesta: El Convenio 169 de la OIT, es un instrumento internacional referente a derechos humanos, por lo que, tiene rango constitucional en todos los países de la región, por lo tanto, el enfoque intercultural que contienen los mandatos del artículo 8 y también de los artículos 9 y 10, deben ser aplicados por las autoridades judiciales y administrativas a través de una herramienta argumentativa denominada por la Corte Interamericana de Derechos Humanos (Corte IDH) como control de convencionalidad.

En efecto, de acuerdo a la doctrina del control de convencionalidad, en cumplimiento a los principios de buena fe (pacta sunt servanda) y efecto útil, las 
autoridades internas, sean jueces o cualquier servidor público, deben aplicar de manera directa y preferente a su normativa interna, el tratado internacional que sea más favorable y coherente con el avance del derecho internacional de los derechos humanos, en este caso, por su situación de histórica discriminación, el más favorable para el ejercicio de los derechos de los pueblos indígenas y sus miembros.

La doctrina del control de convencionalidad fue desarrollada por la Corte $\mathrm{IDH}$, primero en el caso Almonacid Arellano Vs. Chile, que fue la sentencia fundadora de esta línea jurisprudencial y que estableció el método de aplicación directa y preferente de tratados internacionales más favorables a la luz de los principios de buena fe y efecto útil. Posteriormente en el caso Trabajadores Cesados Vs. Perú, la Corte estableció que el control de convencionalidad debe ser realizado de oficio; y, finalmente, en los casos Cabrera García Vs. México y Gellman Vs. Uruguay, estableció que el control de convencionalidad debe ser realizado no únicamente por los jueces, sino también por cualquier servidor público.

Esta doctrina es vinculante para todos los Estados que hayan ratificado la Convención Americana de Derechos Humanos, en ese sentido, la aplicación preferente de instrumentos internacionales sobre derechos humanos, no sólo se limita a los instrumentos interamericanos, ya que la propia Corte IDH, de acuerdo a una interpretación evolutiva, contempla también los derechos contenidos en el Convenio 169 de la OIT.

Por lo señalado, la doctrina del control de convencionalidad es aplicable en toda la región sur de Latinoamérica, lo que significa que toda autoridad jurisdiccional o administrativa de Brasil debe aplicarla y garantizar así la aplicación del Convenio 169 de la OIT.

Pregunta: En la defensa de los derechos humanos de la población amazónica, ¿qué significa un argumento jurídico con respecto a la dimensión cultural desde una pluralidad epistemológica? (interculturalidad plurinacional y el buen vivir)

Respuesta: La evolución del Derecho Internacional de los Derechos Humanos, plantea superar la idea de igualdad formal y más bien postula resguardar la 
igualdad real o material, debido a la situación de histórica asimetría y jerarquización en la que se encuentran sectores históricamente discriminados, entre ellos los pueblos indígenas, las mujeres, las personas lesbianas, gay, bisexuales, trans e intersex (LGBTI), entre otros.

Entonces, tanto los instrumentos internacionales en derechos humanos como los estándares internacionales en esta temática, plantean la aplicación del enfoque diferencial, de género, de interculturalidad y de interseccionalidad, para así identificar las históricas asimetrías y superar barreras de hecho o de derecho que impidan el pleno goce de derechos sin discriminación.

Desde esta perspectiva, el enfoque intercultural, tiene la finalidad de generar construcciones plurales de derechos a través de métodos dialógicos, como los diálogos interjurisdiccionales, los diálogos interculturales y también los peritajes antropológico-culturales. Estos métodos dialógicos consustanciales al enfoque intercultural, aseguran que la voz directa -y no mediada- de los históricamente oprimidos sea el fundamento de cualquier medida o política pública que pueda ser asumida.

Además, el enfoque de interculturalidad es coherente con un pluralismo jurídico igualitario, el cual, tal como ya se señaló, consagra a las normas, procedimientos, cosmovisiones de los pueblos indígenas como fuentes directas de derecho, lo que significa que la ley no es la única fuente normativa y que las autoridades, a partir de una interpretación plural e intercultural del ordenamiento, también deben considerar estas fuentes normativas.

El enfoque intercultural en coherencia con el giro decolonial, asegura también el análisis de medidas, políticas y decisiones judiciales en el marco del respeto de otros saberes, de diversas espiritualidades, de distintos sistemas políticos y económicos y también de otras formas de democracia, como la comunitaria.

En este marco, el modelo constitucional boliviano, en coherencia con la interpretación intercultural, ha diseñado el paradigma del vivir bien, el cual, desde un enfoque intercultural, plantea un esquema de derechos fundamentales que supera la visión antropocéntrica y más bien asume el paradigma biocéntrico, a partir del cual, la madre tierra y todo ser sintiente, entre ellos los animales, son titulares de derechos, los cuales además, en base al equilibrio, la relacionalidad 
y la complementariedad, coexisten con los derechos individuales, colectivos y otros derechos trans-individuales, para vivir bien y en armonía.

De acuerdo a lo señalado, puede establecerse que el paradigma del vivir bien será la base para una argumentación jurídica plural que desde una visión biocéntrica y de complementariedad, coherente con un sistema plural de fuentes jurídicas y una pluralidad epistémica, permita construir pluralmente derechos, considerando la voz de los históricamente oprimidos, generando así una interculturalidad plurinacional en constante construcción para vivir bien.

Pregunta: Si el estado de derecho sostenido por el constitucionalismo liberal está marcado por visiones monoculturales, hegemónicas y colonialistas del Estado, ¿cómo se pueden comprender las nociones de justo e injusto en realidades tan diferentes como las de los países andino-amazónicos? ¿En su opinión, se puede afirmar que la búsqueda del diálogo jurídico está basada en un permanente ejercicio de cuestionamiento de la supremacía de la ley para el reconocimiento de los principios y derechos fundamentales?

Respuesta: El constitucionalismo liberal en Latinoamérica, restringió la ciudadanía a hombres blancos, letrados y no sujetos a servidumbre doméstica, excluyendo del ejercicio de elegir y ser elegido a mujeres y miembros de pueblos indígenas. En este contexto, las leyes, como única fuente de derecho, fueron el reflejo de esta visión de esta ciudadanía restringida que generó una impronta no solamente de monoculturalidad, sino también de exclusión y discriminación y que desde la homogeneización concibió formulaciones de justica abstractas descontextualizadas y en la mayoría de los casos discriminatorias para los históricamente oprimidos.

Las luchas emancipatorias de los pueblos indígenas en Latinoamérica y los avances en el derecho internacional de los derechos humanos, por ejemplo con la aprobación del Convenio 169 de la OIT y luego con otros instrumentos como la Declaración de Naciones Unidas sobre derechos de los pueblos indígenas o la Declaración Americana de derechos de los pueblos indígenas, plantearon horizontes plurales y propicios para las construcciones plurales de derechos, cuestionando de esta manera el positivismo jurídico recalcitrante 
basado en formulaciones legales abstractas que desconocían la diversidad cultural y las históricas asimetrías en las que se encontraban y aún se encuentran los pueblos indígenas y otros sectores históricamente oprimidos.

En este escenario emancipatorio, tal como ya se señaló, el giro decolonial postula la idea de complementariedad y desjerarquización de los diferentes saberes y el reconocimiento a un pluralismo jurídico igualitario, lo que significa superar una visión homogeneizante de la justicia, y más bien, de acuerdo a criterios de igualdad sustantiva y no discriminación, construir pluralmente derechos desde la voz de los históricamente oprimidos, desde sus cosmovisiones, su diversidad cultural y considerando su particular situación en modelos de Estado históricamente excluyentes.

Por lo anotado, la justicia en clave plural y en coherencia con el giro decolonial, plantea la necesidad de implementar modelos polifónicos de justicia, los cuales a partir de diálogos interculturales e interjurisdiccionales apliquen enfoques interculturales en base a argumentaciones plurales destinadas a consagrar la justicia desde el lente intercultural y a partir de la voz de los históricamente oprimidos.

Sin duda, estos modelos polifónicos de justicia constitucional que propician diálogos interculturales e interjurisdiccionales en aras de generar procesos de traducción y entendimiento destinados a su construcción plural, son coherentes con el paradigma del vivir bien ya explicado y con un pluralismo jurídico de tipo igualitario, en el cual existe un pluralismo de fuentes jurídicas, que supera la visión de la ley como única fuente directa de derecho.

Lo descrito precedentemente, evidencia una superación del principio del imperio de la ley, el cual era coherente con un modelo de Estado monista y monocultural, y más bien, propicia la construcción plural de derechos en un esquema biocéntrico y de complementariedad, armonía y reciprocidad para vivir bien.

Pregunta: En Bolivia, después de diez años de la Constitución de 2009, ¿qué evaluación se puede hacer sobre la construcción del ideal de una "comunidad y descolonización del constitucionalismo plurinacional"? 
Respuesta: La Constitución boliviana de 2009, luego de un proceso constituyente plural, diseñó un modelo de Estado constitucional plurinacional comunitario de derechos que supera al Estado legicentrista de derecho y también a la formulación eurocéntrica del Estado constitucional de derecho.

El rasgo del Estado constitucional en clave dialógica y plural, se evidencia en los tres principios esenciales del modelo constitucional vigente contenidos en el art. 109.I de la Constitución: El de igual jerarquía, el de aplicación directa y directa justiciabilidad de derechos.

El primer principio, es decir de igual jerarquía de derechos, supera la teoría generacional de derechos (derechos de primera y segunda generación) y más bien desde el paradigma del vivir bien, plantea la coexistencia en igual jerarquía de los derechos individuales, colectivos y transindividuales, entre ellos los derechos de la Madre Tierra.

Todos estos derechos jerárquicamente iguales, tienen una aplicación directa y preferente, lo que consagra el valor normativo de la Constitución y un modelo argumentativo plural basado en los enfoques diferencial, de género, intercultural e interseccional. Por tanto, las autoridades judiciales, administrativas y también las autoridades indígenas originaria campesinas, deben aplicar y materializar estos derechos contenidos en el bloque de constitucionalidad a partir de construcciones dialógicas propias de modelos polifónicos de justicia constitucional y en el marco de un pluralismo jurídico de tipo igualitario.

Además, el principio de directa justiciabilidad, consagra la protección tutelar de derechos individuales, colectivos y transindividuales, a través de las acciones de libertad, amparo, protección de privacidad, cumplimiento, y popular. En este marco, los derechos económicos, sociales, culturales y ambientales DESCA, son abordados en clave intercultural y ya no son cláusulas programáticas, sino más bien, de acuerdo al diseño vigente pueden ser tutelados a través de los mecanismos tutelares antes descritos.

Este esquema constitucional, con sustento en el paradigma del vivir bien -el cual ya fue explicado- y enmarcado en un modelo polifónico de justicia constitucional se enmarca en un constitucionalismo plurinacional comunitario y descolonizador. También la igualdad jerárquica de la jurisdicción indígena 
originaria campesina con la ordinaria y la agroambiental y un pluralismo jurídico igualitario caracterizan este tipo de constitucionalismo.

Lamentablemente, la Constitución de 2009 que se enmarca en este constitucionalismo plurinacional comunitario y descolonizador, a más de diez años de su vigencia, todavía no ha podido ser materializada porque aún pervive la cultura monocultural, excluyente y discriminadora de los operadores del sistema de justicia, de las autoridades del órgano ejecutivo, del órgano legislativo y electoral.

Pregunta: ¿Podría explicar qué es la "Ley de Deslinde Jurisdiccional" y sus derivaciones para la jurisprudencia indígena que se originaría en el campesinado?

Respuesta: Para responder esta pregunta, en primer lugar es importante señalar que la Constitución boliviana de 2009, en su artículo segundo consagra el derecho a la libre-determinación de las naciones y pueblos indígena originario campesinos, como un término integral que contempla a los pueblos indígenas (pueblos de tierras bajas o de la Amazonía), pueblos originarios (pueblos de tierras altas o andinos) y campesinos (pueblos indígenas de los valles en los cuales tuvo un impacto directo la reforma agraria iniciada en 1952, la cual utilizó la denominación de campesinos).

En este contexto, debe señalarse que la Constitución boliviana, en el artículo 179.II consagra la igualdad jerárquica de la jurisdicción indígena originaria campesina en relación a la jurisdicción ordinaria, agroambiental y las jurisdicciones especializadas. En este sentido, se establece un ámbito de aplicación personal, material y territorial para el ejercicio de la jurisdicción indígena originaria campesina, reenviando la delimitación de estos aspectos a una Ley de Deslinde Jurisdiccional.

La Ley No. 73 de 29 de diciembre de 2010, denominada Ley de Deslinde Jurisdiccional, desarrolla los ámbitos de vigencia entre la jurisdicción indígena originaria campesina y las otras jurisdicciones y también establece los mecanismos de coordinación y cooperación interjurisdiccional en el marco del pluralismo jurídico igualitario. 
Esta disposición legal, en el artículo noveno regula el ámbito de protección personal, al señalar que están sujetos a la jurisdicción indígena originaria campesina los miembros de la nación y pueblo indígena originario campesino. Asimismo, en el artículo 10 disciplina el ámbito de vigencia material de esta jurisdicción y desde una lógica absolutamente contraria al giro decolonial y a los principios de plurinacionalidad y pluralismo, en el parágrafo segundo, detalla las materias que no puede conocer la jurisdicción indígena originaria campesina, entre estas:

a) En materia penal, los delitos contra el Derecho Internacional, los delitos por crímenes de lesa humanidad, los delitos contra la seguridad interna y externa del Estado, los delitos de terrorismo, los delitos tributarios y aduaneros, los delitos por corrupción o cualquier otro delito cuya víctima sea el Estado, trata y tráfico de personas, tráfico de armas y delitos de narcotráfico. Los delitos cometidos en contra de la integridad corporal de niños, niñas y adolescentes, los delitos de violación, asesinato u homicidio;

b) En materia civil, cualquier proceso en el cual sea parte o tercero interesado el Estado, a través de su administración central, descentralizada, desconcentrada, autonómica y lo relacionado al derecho propietario;

c) Derecho Laboral, Derecho de la Seguridad Social, Derecho Tributario, Derecho Administrativo, Derecho Minero, Derecho de Hidrocarburos, Derecho Forestal, Derecho Informático, Derecho Internacional público y privado, y Derecho Agrario, excepto la distribución interna de tierras en las comunidades que tengan posesión legal o derecho propietario colectivo sobre las mismas;

d) Otras que estén reservadas por la Constitución Política del Estado y la Ley a las jurisdicciones ordinaria, agroambiental y otras reconocidas legalmente.

Finalmente, esta ley, en el artículo 11 establece que el ámbito de vigencia territorial se aplica a las relaciones y hechos jurídicos que se realizan o cuyos efectos se producen dentro de la jurisdicción de un pueblo indígena originario campesino, siempre y cuando concurran los otros ámbitos de vigencia establecidos en la Constitución y esta Ley.

Lo descrito precedentemente, concretamente en cuanto al ámbito de vigencia material, evidencia la pervivencia de una visión aún monocultural, excluyente y discriminadora de una Asamblea Legislativa Plurinacional, perspectiva contraria al giro decolonial y a los principios de plurinacionalidad, pluralismo e interculturalidad, ya que una ley, de manera contraria a la Constitución, limita el ejercicio pleno de la jurisdicción indígena originaria campesina y para ello utiliza una clasificación del derecho de fuente liberal 
(derecho penal, civil, etc.), reduciendo sus atribuciones a hechos de bagatela en el marco nuevamente de una epistemología hegemónica.

En relación a esta ley, el Tribunal Constitucional Plurinacional ha tenido algunos avances interpretativos importantes, entre ellos en la SCP 0026/2013 de 15 de enero de $2013^{4}$, emergente del proceso constitucional de conflicto interjurisdiccional de competencias (Art. 202.11 de la Constitución) ${ }^{5}$. En esta decisión, el máximo contralor de constitucionalidad ha brindado una interpretación extensiva al ámbito de competencia personal de la jurisdicción indígena originaria campesina y ha establecido que están sometidas a esta no sólo los miembros de un pueblo indígena, sino también terceros que se sometan a esta jurisdicción de manera tácita o expresa.

Asimismo, el Tribunal Constitucional Plurinacional, en la SCP 0037/2013 de 4 de enero de $2013^{6}$, también emergente de un conflicto interjurisdiccional de competencias, no solo estableció un precedente en vigor referente al acceso a la justicia en clave plural, sino que también, de acuerdo a pautas constitucionalizadas de interpretación, brindó al artículo 10 de la Ley de Deslinde Jurisdiccional (ámbito de competencia material) un sentido conforme al bloque de constitucionalidad, en ese sentido preciso que el conocimiento y resolución de los asuntos parte de una comprensión integral, desde un sentido de totalidad, entendiendo el conflicto como una unidad en la que ingresa lo espiritual y otros aspectos basados en saberes distintos.

En el contexto anotado, de acuerdo a la cláusula constitucional de libre determinación, estableció también que cada pueblo indígena tiene su propio sistema jurídico, acorde con su cosmovisión, con su cultura, tradiciones, valores, principios y normas, por lo que, en virtud a estos criterios determinan los asuntos que resolverán y en su caso sancionarán, lo que implica que tienen competencia para conocer los hechos que siempre han conocido y resuelto, sin que estén limitados por las clasificaciones realizadas por el tenor literal de la citada ley.

Lo cierto es que, a pesar de estos estándares jurisprudenciales más altos, las propias autoridades, incluidas la de la justicia constitucional, desconocen este

\footnotetext{
${ }^{4}$ Sentencia disponible en:

https://buscador.tcpbolivia.bo/_buscador/(S(lii4yxee3ai0bzvka4v3qht4))/WfrResoluciones1.aspx

${ }^{5}$ Ibid.

${ }^{6}$ Ibid.
} 
criterio y la jurisdicción indígena originaria campesina no ha tenido un ejercicio coherente con el diseño constitucional, lo que grafica el grave problema de la brecha de implementación constitucional en el Estado Plurinacional de Bolivia.

Pregunta: Teniendo en cuenta la violación sistemática de los derechos humanos y socioambientales en la Amazonía, ¿cómo evalúa la representatividad de la población tradicional en las organizaciones internacionales (OOII) de derechos humanos? ¿No son las OOII, en cierta medida, parte de la estructura misma que garantiza la opresión de los pueblos tradicionales?

Respuesta: Todavía las estructuras de las OOII tienen fundamento en una epistemología hegemónica con poca participación directa en estructuras de debate y decisión de los pueblos indígenas, por lo que, es importante reflexionar sobre la incidencia que debe tener el giro decolonial en el derecho internacional. Justamente, esta falta de representación es el fundamento desde el enfoque intercultural, para cuestionar la omnipotencia del principio de universalidad de los derechos, y más bien consagrar, a través de mecanismos dialógicos, procesos de traducción-entendimiento en aras de realizar construcciones plurales de derechos coherentes con el paradigma del vivir bien, para evitar así la pervivencia de prácticas hegemónicas impuestas desde el derecho internacional y los OOII.

Pregunta: Según su experiencia profesional y académica, ¿cuáles son los principales desafíos para superar las profundas desigualdades sociales en la región amazónica y consolidar la legitimidad de los derechos? ¿Podrías comentar sobre la Amazonía brasileña?

Respuesta: Considero que uno de los desafíos más importantes para una real materialización de derechos es la consolidación de un sistema plural de control de constitucionalidad en coherencia con modelos polifónicos de justicia constitucional que permitan consolidar el paradigma del vivir bien y materializar la justicia en clave plural y desde enfoques de interculturalidad, género e interseccionalidad. 
En el caso boliviano, se ha diseñado un sistema plural de control de constitucionalidad, en el cual, el Tribunal Constitucional Plurinacional, es el máximo garante de la Constitución y del Bloque de Constitucionalidad. En este escenario, la Constitución boliviana, en el art. 197.II señala que esta instancia estará compuesta por magistradas y magistrados elegidos con criterios de plurinacionalidad, con representación del sistema ordinario y del sistema indígena originario campesino.

Al respecto, es importante realizar reflexiones relevantes en cuanto a la forma de elección de magistradas y magistrados del Tribunal Constitucional Plurinacional boliviano, ya que éstos, de acuerdo a lo establecido por el artículo 198 de la Constitución, son elegidos mediante sufragio universal (al igual que las y los magistrados del Tribunal Supremo de Justicia, del Tribunal Agroambiental y del Consejo de la Magistratura).

En el caso de las magistradas y magistrados del Tribunal Constitucional Plurinacional, el artículo 197 -como ya se señaló-, prescribe el cumplimiento de criterios de plurinacionalidad para una composición plural, los cuales, en una interpretación sujeta al principio de unidad constitucional, debieran asegurar el ejercicio de la democracia comunitaria contenida en el artículo 11.3, es decir, que para cumplir con el indicado criterio, las y los magistrados que representen al sistema indígena originario campesino, debieran ser elegidos a través de normas y procedimientos propios de los pueblos indígenas, en el marco del ejercicio de sus sistemas políticos y formas de organización.

Lamentablemente, nuevamente la ley monocultural, mutila el mandato constitucional contenido en el artículo 197, ya que la Ley del Tribunal Constitucional Plurinacional de 6 de julio de 2010 en su artículo 13 establece que al menos dos magistradas y magistrados provendrán del sistema indígena originario campesino por autoidentificación personal, omitiendo señalar en coherencia con el artículo 11.3 de la Constitución (democracia comunitaria), que estos miembros -para asegurar una real composición plural-, deben ser elegidos por las naciones y pueblos indígena originario campesinos a través de sus sistemas organizativos, normas y procedimientos.

Por una interpretación incoherente de la Ley con la Constitución del Órgano Electoral Plurinacional y también de la Asamblea Legislativa 
Plurinacional, en las dos elecciones realizadas desde la vigencia de la Constitución, las candidatas y candidatos autoidentificados con un pueblo indígena, fueron preseleccionados por la Asamblea Legislativa Plurinacional, también fueron elegidos por sufragio universal y no por mecanismos de democracia comunitaria. La mayoría de estos magistrados o magistradas autoidentificadas con un pueblo indígena, jamás tuvieron experiencia alguna en la jurisdicción indígena originaria campesina.

Esta forma primero de preselección por la Asamblea Legislativa Plurinacional y luego por sufragio universal, a pesar del diseño constitucional basado en la plurinacionalidad, evidencia la prevalencia de visiones monoculturales propias de una concepción liberal de modelo de Estado y advierte la vigencia de una cultura de discriminación y menosprecio a las otras formas de democracia y a los derechos de libre-determinación de las naciones y pueblos indígena originario campesinos.

En un Estado plurinacional, como es el caso boliviano, en el cual todavía no se ha superado las visiones monoculturales, la elección por los pueblos indígenas de las y los magistrados autoidentificados con ellos era esencial para materializar interpretaciones interculturales de derechos y consolidar procedimientos interculturales acordes con el giro decolonial que superen formalismos y ritualismos extremos y que generen métodos dialógicos de construcción de derechos para vivir bien y en armonía; y también era esencial para garantizar la independencia judicial en el marco de nuevas formas descolonizadas de composición plural.

Lamentablemente la promesa de plurinacionalidad fue incumplida por varias razones, una de ellas la ausencia de composición plural en el Tribunal Constitucional Plurinacional. Esta es una de las causas, para que las desigualdades sociales no se hayan reducido y también es una razón por la cual, la discriminación y violación sistémica de derechos de los pueblos indígenas andinos y amazónicos no hayan sido eficazmente reparados.

Para asegurar una real igualdad material, también considero importante la formulación de políticas públicas dialógicas a partir de las voces de los históricamente oprimidos, para que así, las medidas que sean asumidas tengan 
un impacto real en los pueblos indígenas y sus miembros, quienes vivieron una historia de discriminación y exclusión.

Es también esencial garantizar la participación política de los pueblos indígenas en órganos representativos del Estado, para así superar las históricas improntas monoculturales de estas instancias y generar una cultura de diálogo, complementariedad y armonía en clave multicultural.

También será esencial fortalecer la democracia comunitaria, la cual no sólo debe ser aplicable en el Estado Plurinacional de Bolivia, sino también en toda Latinoamérica por su reconocimiento en instrumentos internacionales como la Declaración de Naciones Unidas sobre derechos de los pueblos indígenas (Artículos 3, 4, 5, 18, 20 y 34) y también en la Declaración Americana sobre derechos de los pueblos indígenas (artículos II, III, IV, XIII.3, XXI.2, XXIII.1).

La academia también debe tener profundos cambios, ya que este es un espacio que siempre ha excluido a los históricamente oprimidos, por lo que debe existir una voluntad de apertura al diálogo y una participación directa de los pueblos indígenas en el marco del reconocimiento y respeto a los diversos saberes y las diferentes cosmovisiones de las culturas diversas.

Las universidades, instancias de formación de jueces, fiscales y otros servidores públicos, debieran también incluir en sus currículos las materias de pluralismo jurídico, derechos humanos, argumentación jurídica plural, entre otras materias, para superar así una visión predominantemente monocultural.

En Brasil y en los demás países de la región, el control de constitucionalidad tampoco ha sido lo suficientemente eficaz para la tutela de derechos colectivos de pueblos indígenas, en gran medida por la visión monocultural de las autoridades jurisdiccionales y por los graves problemas de independencia judicial que enfrentan las altas cortes en Latinoamérica.

Pregunta: La constitución boliviana considera que la naturaleza es un sujeto de derechos. ¿Cuáles son los impactos de esto en la preservación del medio ambiente y la forma en que se estructuran las relaciones humanas con la naturaleza, y cómo se ha garantizado este derecho en el sistema judicial boliviano? 
Respuesta: Ya se señaló que el paradigma del vivir plantea la superación de una visión antropocéntrica y más bien postula una concepción biocéntrica, a partir de la cual, la madre tierra y todo ser sintiente son titulares de derechos, los cuales deben ser ejercidos en armonía, complementariedad y reciprocidad con derechos individuales, colectivos de los pueblos indígenas y otros derechos transindividuales, como por ejemplo la salubridad pública.

La plurinacionalidad es consustancial al paradigma del vivir bien y a la superación de una visión antropocéntrica de derechos; $y$, aunque la Constitución boliviana -a diferencia de la ecuatoriana-, no reconoce en términos textuales la titularidad de derechos de la madre tierra, esta concepción emerge de la naturaleza misma del modelo de Estado y esa debe ser la interpretación que debe brindar a este tema el Tribunal Constitucional Plurinacional, aunque esta es aún una tarea pendiente para esta instancia plural de control de constitucionalidad.

En el caso boliviano, fue la Ley No. 71 de 21 de diciembre de 2010, denominada Ley de Derechos de la Madre Tierra, la que de manera taxativa reconoció los derechos de la Madre Tierra y estableció las obligaciones y deberes del Estado Plurinacional y de la sociedad para garantizarlos.

En el contexto señalado, en el artículo séptimo se estableció que la Madre Tierra tiene derecho a la vida, entendido como el derecho al mantenimiento de la integridad de los sistemas de vida y los procesos naturales que los sustentan, así como las capacidades y condiciones para su regeneración. También se estableció que la Madre Tierra tiene derecho a la diversidad de la vida, el cual se comprende como el derecho a la preservación de la diferenciación y la variedad de los seres que componen la Madre Tierra, sin ser alterados genéticamente ni modificados en su estructura de manera artificial, de tal forma que se amenace su existencia, funcionamiento y potencial futuro.

Se establece también que la Madre Tierra tiene derecho al agua, que es el derecho de preservación de la funcionalidad de los ciclos del agua, de su existencia en la cantidad y calidad necesarias para el sostenimiento de los sistemas de vida y su protección frente a la contaminación para la reproducción de la vida de la Madre Tierra y todos sus componentes. 
La Madre Tierra tiene también derechos al aire limpio, que es el derecho a la preservación de la calidad y composición del aire para sostenimiento de los sistemas de vida y su protección frente a la contaminación, para la reproducción de la vida de la Madre Tierra y todos sus componentes.

El derecho al equilibro, como derecho de la Madre Tierra, es el derecho al mantenimiento o restauración de la interrelación, interdependencia, complementariedad y funcionalidad de los componentes de la Madre Tierra, de forma equilibrada para la continuación de sus ciclos y la reproducción de sus procesos vitales.

Por su parte, la Madre Tierra, tiene derecho a una oportuna y efectiva restauración de los sistemas de vida afectados por las actividades humanas. Finalmente, la referida ley, consagra el derecho a vivir libre de contaminación, entendido como el derecho a la preservación de la Madre Tierra de contaminación de cualquiera de sus componentes, así como de residuos tóxicos y radioactivos generados por las actividades humanas.

Posteriormente, la Ley Marco de la Madre Tierra No. 300 de 15 de octubre de 2012, también de manera expresa y en armonía con el modelo constitucional vigente, consagró a la Madre Tierra no como objeto de protección, sino más bien como titular de derechos, en este marco, de manera textual en el art. 4.1.a estableció a la Madre Tierra como sujeto colectivo de interés púbico, derecho que debe ser ejercido en armonía e interdependencia con otros derechos individuales, colectivos y transindividuales para la construcción de una sociedad justa, equitativa y solidaria.

En el contexto señalado, los derechos de la Madre Tierra, tienen en el Estado Plurinacional de Bolivia un mecanismo de directa justiciabilidad, es decir un procedimiento tutelar destinado a proteger sus derechos, este mecanismo es la acción popular, la cual se caracteriza por tener un diseño constitucional emancipatorio y coherente con el giro decolonial y que en revisión es conocida por el Tribunal Constitucional Plurinacional en cualquiera de sus cuatro salas.

Lo expresado precedentemente, evidencia el cambio de paradigma y la influencia del giro decolonial y de los principios de plurinacionalidad, pluralismo e interculturalidad en la teoría de los derechos fundamentales; sin embargo, el modelo extractivista, la visión monocultural y la falta de composición plural y de 
independencia judicial del Tribunal Constitucional Plurinacional, a pesar del potencial emancipatorio de la acción popular, han sido la causa para que los derechos de la Madre Tierra no hayan tenido una eficacia y una tutela adecuada en el Estado boliviano, así lo evidencian casos emblemáticos como el del TIPNIS o el de la reserva de Tariquía, los cuales, implicaron flagrantes vulneraciones a derechos de la Madre Tierra y derechos de los pueblos indígenas, vulneraciones que no fueron tuteladas ni reparadas por el Tribunal Constitucional Plurinacional.

Pregunta: En su opinión, ¿en qué medida las fronteras nacionales, con las cuales los proyectos de poder político y económico están normalmente vinculados, pueden representar obstáculos para el desarrollo de mecanismos de protección ambiental y la implementación de políticas destinadas a garantizar los derechos y una buena vida para las poblaciones tradicionales?

Respuesta: En mi opinión, esta pregunta está íntimamente vinculada con todos los aspectos antes abordados, en ese sentido, es innegable, que tanto en el Estado Plurinacional de Bolivia, como en Latinoamérica, está enraizado y vigente un modelo extractivista contrario a un paradigma del vivir bien, el cual, sin un eficaz control plural de constitucionalidad, cooptará por completo los poderes públicos y evitará de esta forma la materialización de derechos, especialmente en cuanto a la Madre Tierra y a los pueblos indígenas.

En el marco de lo afirmado, considero que la vigencia de derechos en clave del giro decolonial, debe tener como presupuesto esencial un máximo contralor de constitucionalidad con composición plural, independiente de los órganos de poder y de otros factores de poder como los ejercidos por las grandes empresas que concentran capitales y que sin duda inciden en las decisiones públicas.

Desde la perspectiva anotada, la independencia del control de constitucionalidad en relación a factores hegemónicos de poder, podría ser alcanzada, entre otras medidas, a través de la reformulación de procesos de selección de candidatos a los altos tribunales en Latinoamérica; también mediante un rediseño de los juicios de responsabilidades a altas autoridades jurisdiccionales, para asegurar así juzgamientos ante instancias con composición plural y con alto grado de independencia. Lo cierto es que en 
Latinoamérica los juicios de responsabilidades, tienen una esencia de juicios políticos definidos por órganos de poder, en la mayoría cooptados por otros factores de poder, como el ejercido por las empresas dedicadas al extractivismo.

Considero también esencial -tal como ya se dijo-, asegurar la composición plural de los órganos legislativos a través de la participación política mediante democracia comunitaria de miembros de pueblos indígenas, esta participación política de los pueblos indígenas en todos los niveles de organización territorial de los Estados es esencial para el giro decolonial y para el respeto de derechos de los históricamente oprimidos.

La presencia y redefinición de objetivos de los OOll será también esencial para una efectiva materialización de derechos colectivos y transindividuales, en este sentido, es esencial que instancias internacionales también resguarden una composición plural con la presencia paritaria de representantes de pueblos indígenas. También será esencial que el derecho internacional de los derechos humanos, supere la idea de exclusividad del principio de universalidad de los derechos y más bien aperture sus horizontes a la construcción plural de derechos a través de métodos de traducción y entendimiento, métodos propios de los enfoques de interculturalidad, género e interseccionalidad.

Pregunta: ¿Cómo percibe las relaciones entre los muchos pueblos indígenas en Bolivia hoy? ¿Es posible hablar de un movimiento indígena boliviano? ¿Cuáles son los principales puntos de aproximación y conflicto entre estos pueblos, considerando sus especificidades (por ejemplo, los pueblos de las tierras altas y los pueblos amazónicos)? ¿Existen organizaciones con aspiraciones de reunir a todos los pueblos indígenas en Bolivia (como CONAIE, en Ecuador) y, de ser así, cuál es su importancia hoy?

Respuesta: Considero que, en el Estado Plurinacional de Bolivia, no es posible sustentar la idea de un solo movimiento indígena, ya que existen varios pueblos indígenas tanto en tierras altas (zona andina), tierras bajas (Amazonía) y tierras medias (valles bolivianos).

En el marco de esta diversidad, existen importantes organizaciones sociales que aglutinan a diversos pueblos indígenas y que tuvieron una 
participación determinante en el proceso constituyente boliviano iniciado el 2006 y que concluyó el año 2009 con la aprobación de la Constitución.

Entre estas organizaciones puede citarse al Consejo Nacional de Ayllus y Markas del Qullasuyo, CONAMAQ, a la Confederación Sindical Única de Trabajadores Campesinos de Bolivia CSUCB, a la Confederación de Pueblos Indígenas del Oriente Boliviano CIDOB, a la Confederación Sindical de Comunidades Interculturales de Bolivia CSCIB; y, a la Confederación Nacional de Mujeres Campesina Indígena Originarias de Bolivia "Bartolina Sisa", instancias que dejaron su voz en el proceso constituyente en el llamado Pacto de Unidad, del cual emergieron las propuestas para un Estado Plurinacional y la restitución territorial, reconstitución de institucionales propias y procesos de igualación a la luz de la garantía de no discriminación.

A más de diez años de vigencia de la Constitución estas instancias perviven; sin embargo, también han surgido otras voces desde los pueblos indígenas que también deben ser consideradas, especialmente en tierras medias.

Es importante destacar también que si bien a partir de la propuesta del Pacto de Unidad, la Constitución asumió la denominación de naciones y pueblos indígena originario campesinos como un término compuesto, no es menos cierto que existen tensiones muy complejas entre pueblos indígenas originarios y comunidades campesinas.

Por ejemplo, en el sur, lugar donde resido, existe un complejo conflicto entre el pueblo indígena de Quila Quila con el sindicato campesino por la titulación de tierras. En el mismo espacio geográfico, el pueblo indígena postula una titulación colectiva de sus tierras ancestrales; y los sindicatos campesinos, conciben la necesidad de una titulación individual de tierras.

Estos conflictos son muy frecuentes especialmente en los valles, zona geográfica en la cual los sindicatos campesinos emergieron del proceso de reforma agraria y cuyas visiones pueden ser contrarias a los pueblos indígenas originarios que resistieron a los procesos de colonización y también a la visión homogeneizante de dicha reforma.

En estos conflictos, sin duda, un Tribunal Constitucional Plurinacional tiene un rol preponderante para la materialización de derechos a través de 
construcciones plurales de precedentes en vigor enmarcados en ponderaciones interculturales emergentes de diálogos interculturales e interjurisdiccionales.

Lamentablemente, las disfunciones estructurales de este máximo contralor de constitucionalidad no brindan muchas esperanzas y más bien reduce cada vez más el ideal del giro decolonial.

Pregunta: ¿Cómo percibe el momento actual en América Latina, en que avanza la extrema derecha y se radicaliza el proyecto neoliberal-colonial, y cómo esto se refleja en la Amazonía y en la vida de los pueblos de la Amazonía?

Respuesta: El monoculturalismo, el abuso de poder, los obstáculos a la participación política de los pueblos indígenas, las estructuras estatales cooptadas por los grandes capitales y la corrupción son escenarios propicios para los proyectos neoliberales y extractivistas. En este contexto, Latinoamérica está en un momento neurálgico de su historia, siendo uno de los mayores retos la implementación de Estados Plurinacionales que en armonía, complementariedad y reciprocidad generen construcciones plurales de derechos en coherencia con el giro decolonial.

Un avance de la extrema derecho y de los proyectos neoliberalescolonialistas, significará una nueva historia de represión, silenciamiento, exclusión y discriminación a los históricamente oprimidos e incluso podría significar su extinción cultural, por eso la importancia de reflexionar en clave de plurinacionalidad, pluralismo e interculturalidad. 